\title{
Physicochemical Parameters for Brea Gum Exudate from Cercidium praecox Tree
}

\author{
Martin A. Masuelli ${ }^{1,2, *}{ }^{-1}$, Aníbal Slatvustky ${ }^{3}$, Ariel Ochoa ${ }^{2}$ and M. Alejandra Bertuzzi ${ }^{3}$ \\ 1 Laboratorio de Investigación y Servicios de Química Física, Área de Química Física, Departamento de \\ Química, Facultad de Química, Bioquímica y Farmacia, Universidad Nacional de San Luis, \\ Ejercito de los Andes 950, San Luis D5700HHW, Argentina \\ 2 Laboratorio de Membranas y Biomateriales-Instituto de Física Aplicada-CONICET-UNSL, Universidad \\ Nacional de San Luis, Ejercito de los Andes 950, San Luis D5700HHW, San Luis, Argentina; \\ aochoa@unsl.edu.ar \\ 3 Instituto de Investigaciones para la Industria Química (CONICET), CIUNSa, Facultad de Ingeniería, \\ Universidad Nacional de Salta, Av. Bolívia 5150, Salta A4408TVY, Argentina; amslavutsky@gmail.com (A.S.); \\ mabertu@gmail.com (M.A.B.) \\ * Correspondence: masuelli@unsl.edu.ar; Tel.: +54-0266-4520300 (ext. 1655)
}

Received: 9 November 2018; Accepted: 11 December 2018; Published: 12 December 2018

\begin{abstract}
Brea gum (BG) is a hydrocolloid obtained as an exudate from the Cercidium praecox tree. The physicochemical properties of brea gum are similar to those of the arabic gum and, in many cases, the former can replace the latter. The brea gum was incorporated in 2013 into the Argentine Food Code because of its ancestral background and its current food uses. Brea gum could be also used as additive or excipient for pharmacological formulations. This work reports intrinsic viscosity, coil overlap, and Mark-Houwink-Kuhn-Sakurada (MHKS) parameters of BG solutions. Partially hydrolyzed BG solution was analyzed using intrinsic viscosity measurements, dynamic light scattering and size-exclusion chromatography (SEC). The MHKS parameters, $a$ and $k$, were determined for BG at $25^{\circ} \mathrm{C}$, with values of 0.4133 and $0.1347 \mathrm{~cm}^{3} \mathrm{~g}^{-1}$, respectively. The viscometric molecular weight of BG was $1890 \mathrm{~kg} \mathrm{~mol}^{-1}$. The hydrodynamic parameters of BG were indicative of a hyperbranched structure and spherical conformation. The knowledge obtained on the physicochemical properties of brea gum favors its use in food and pharmaceutical applications.
\end{abstract}

Keywords: brea gum; intrinsic viscosity; Mark-Houwink-Kuhn-Sakurada parameters; molecular weight

\section{Introduction}

Gums are polysaccharides that present the characteristics of modifying the rheological properties of the solvent in which they are dissolved, usually water (as a universal solvent). Gums are used as gelling agents, thickeners, emulsifiers and stabilizers. When gums are dissolved in water, there is a change in the hydrodynamic volume of the high-molecular-weight biopolymers, as well as in the interactions between the biopolymer chains (Wareing [1], Yaseen et al. [2]). These properties have been developed for use in food production because of their functionality for modifying textural attributes and mouth feel (Verbeken et al. [3]).

Brea gum (BG) is a biopolymer obtained as an exudate from the brea tree (Cercidium praecox (Ruiz \& Pavon)). The genus Cercidium belongs to the family Fabaceae and presents two very common species in Argentina, Cercidium praecox (brea tree) and Cercidium australe (brea shrub). Thanks to their root system, the brea trees can prosper in the phytogeographic region of the great Argentine Chaco (semi-arid region). Their ecological importance derives from their ability to colonize degraded land 
and repopulate desert areas. Brea trees grow scattered in the wild, and the gum from these trees is collected manually. The exudate is purified by a simple process of dissolution and drying, and is then milled into a fine powder. BG has functional properties similar to those of other plant gums widely used in the food industry, such as arabic gum (AG) (Bertuzzi et al. [4]). It is therefore likely that BG is incorporated into food production as a thickening additive, and emulsifying and stabilizing agent.

The native populations of Argentina have traditionally used BG as a sweet since pre-Columbian times. It does not produce harmful consequences for human and arboreal health (there is no deforestation of Cercidium praecox). Ancestrally, BG was used as a type of candy, syrup, jam, lodge and tea. Von Müller et al. [5] reported a toxicological evaluation of BG in mice, and evinced that feeding BG to mice at levels of up to $5 \%$ does not cause any toxicological effects, which was used as support for its authorization as a food additive.

When BG is exuded by the tree, its colour is amber and has a semi-liquid consistency with a slightly sweet flavour. BG is highly soluble in water and forms homogeneous and acid solutions with a $\mathrm{pH}=4$. This gum contains residues of D-xylose, L-arabinose, D-glucuronic acid and 4-O-methyl-D-glucuronic acid (Cerezo et al. [6]), with small amounts of proteins that favour the formation of foams and present emulsifying properties. The BG structure presents a $\beta$ - $(1 \rightarrow 4)$-linked D-xylan backbone (possibly containing some $(1 \rightarrow 2)$-linkages) that is heavily 2 -substituted by short branch-chains containing residues of D-xylose, L-arabinose and D-glucuronic acid (Cerezo et al. [6]). It could be said that BG is a polyxylose.

The steps in the purification process include: 1-grinding, 2-dissolution, 3-decantation, 4-filtration, 5-bleaching, and 6-drying. BG is insoluble in organic solvents, without components comprising hydrolysable sugars. No presence of starch, dextrin or tannin was detected. It is notable that BG collected from Argentina and Venezuela shows few changes in composition (galactose and galacturonic acid content) (Ministerio de Agricultura, Ganaderia y Pesca, República Argentina, 2010, [7]). Leon de Pinto et al. [8,9] have reported detailed studies of the composition of BG exudate from nine specimens of Cercidium praecox of Venezuela.

Other works have confirmed the existence of similarities between BG and arabic gum (AG), but those similarities were focused on hydrodynamic behavior rather than chemical structure. AG can be considered as a poly-arabinogalactan and BG as a polyxylose. AG has also been extensively described by Verbeken et al. [3], Tischer et al. [10] and Qi Wang et al. [11]. The physicochemical and functional properties of a BG solution were recently described by Bertuzzi et al. [4]. These authors concluded that BG has adequate functional characteristics for use as an emulsifier, thickener and stabilizer.

Castel et al. [12] worked on fractionating BG by using hydrophobic-interaction chromatography, and fractions were analysed by size-exclusion chromatography. The first gum fraction was $\approx 84 \%$ of the polysaccharides with molecular weight of $2790 \mathrm{kDa}$; the second fraction was $\approx 16 \%$ of the polysaccharides-proteins with a molecular weight of 19,200 kDa; and the third fraction consisted of protein species with a wide range of molecular weights ranging from 6.5 to $66 \mathrm{kDa}$, corroborated by SDS-PAGE.

BG was used as film-forming and biodegradable food packaging material (Bertuzzi \& Slavutsky group [13-15], Spotti et al. [16], Mellinas et al. [17]). BG was used in food applications (Bertuzzi et al. [4] and López \& Jiménez [18], Castel et al. [19], Lopez \& Goldner [20], Lopez et al. [21]).

Viscosity measurements determine the additional amount of local energy dissipation produced when biopolymers are dissolved into a solvent. The intrinsic viscosity of a polysaccharide in a water solution depends on its molecular characteristics, such as molecular weight, shape, size, volume, surface charge, and ease of deformation; as well as on ambient factors, such as temperature, $\mathrm{pH}$, ionic strength, and solvent. Intrinsic viscosity is a parameter related to molecular conformation, although it does not offer a high resolution in terms of molecular structure, as do other methods such as light scattering, size-exclusion chromatography (SEC), osmometry, equilibrium sedimentation and so on. 
The measurement technique has good performance, it is very economical, and can be verified with dynamic light scattering (DLS) and SEC.

The BG studies were performed in dilute aqueous solution using intrinsic viscosity, DLS, and SEC using dextrans for calibration. The hydrodynamic properties of $B G$, in a dilute solution, were measured in order to determine its conformational characteristics. Data on its intrinsic viscosity $([\eta])$ and viscometric molecular weight $\left(\mathrm{M}_{\mathrm{V}}\right)$ were analyzed in order to obtain characteristic parameters such as hydrodynamic radius $\left(R_{H}\right)$, Simha number $\left(v_{(a-b)}\right)$, Perrin parameter $(P)$, hydration value $(\delta)$ and so on. The viscometric molecular weight $\left(\mathrm{M}_{\mathrm{V}}\right)$ was corroborated by determining the molecular weight by DLS (MLS) and by SEC (M $\left.\mathrm{M}_{\mathrm{GPC}}\right)$.

\section{Materials and Methods}

\subsection{Brea Gum Extraction, Purification and Hydrolysis}

The BG exudate from Cercidium praecox was collected in the form of small drops or tears from the province of Salta, Argentina. The purification process included steps of grinding, dissolution, decantation, filtration, and oven-drying at temperatures of $50{ }^{\circ} \mathrm{C}$, then grinding again to a fine powder (ASTM mesh 80). BG solutions of $0.1,0.25,0.5,0.75$ and $1.0 \mathrm{wt} \%$ were then prepared by mixing the desired amount of BG powder with bi-distilled water. Arabic gum was provided by Stanton (Argentina).

In order to study BG fractions, acid hydrolysis was performed using $\mathrm{HCl}$ (Ciccarelli S.A., Argentina) in concentrations of $0.01,0.05,0.1$ and $0.5 \mathrm{M}$, stirring for 1 hour at $80^{\circ} \mathrm{C}$. Polysaccharides were separated and purified using three different ethanol-water mixtures $(70 / 30,80 / 20$ and 90/10 $v / v$ ). After precipitation, the precipitate was washed with ethanol and dried at $40{ }^{\circ} \mathrm{C}$. The fraction of polysaccharide obtained was labeled as pure BG, and the hydrolysates were labeled as BG0.01, BG0.05, BG0.1 and BG0.5.

\subsection{Size-Exclusion Chromatography (SEC)}

SEC was performed on Gilson (Middleton, WI, USA) equipment using a refractive index detector. The column used was a PolySec-GFC-P5000, using bi-distilled water as mobile phase at $0.8 \mathrm{~mL} \mathrm{~min}{ }^{-1}$. Dextran solutions in a proportion of $0.1 \mathrm{wt} \%$ were used to produce the SEC calibration curve.

To carry out the intrinsic viscosity measurements and to perform SEC calibration curves, dextran with molecular weights of $8.8,40,71.9,110,200,580$ and $2000 \mathrm{~kg} \mathrm{~mol}^{-1}$ were used. Dextran solutions were prepared with bi-distilled water in proportions of $0.25-1.0 \mathrm{wt} \%$ for intrinsic viscosity and $0.1 \mathrm{wt} \%$ for SEC.

\subsection{Dynamic Light Scattering}

The determination of the size of the colloidal particles, as well as the particle size distribution of polymers or biopolymers, can be carried out using the dynamic light scattering method (also known as photon correlation spectroscopy), with the Delsa Nano C Instrument (Beckman Coulter, Brea, CA, USA), equipped with a $658 \mathrm{~nm}$ diode laser, and using a $15^{\circ}$ scatter angle. The measurements were made in triplicate for all the samples, each one being the average of at least 10 executions at $25^{\circ} \mathrm{C}$. These measurements were made in dispersions of $0.01 \mathrm{wt} \%$ in $0.01 \mathrm{~mol} \mathrm{~L}^{-1}$ of NaCl, in the absence of particles with a size in the range of 1-1000 nm with a refractive index of 1.3328 . The maximum specification of the particle size range for the instrument is from $0.3 \mathrm{~nm}$ to $5 \mu \mathrm{m}$ in diameter [22-24].

The phenomena of auto-aggregation of polysaccharides is well known, since they are susceptible to produce it. The presence of these aggregates could be attributed to a specific fraction of the sample. The aggregates can cause poor reproducibility of the hydrodynamic radius $\left(\mathrm{R}_{\mathrm{HDLS}}\right)$ obtained (errors greater than $10 \%$ ), and therefore they must be eliminated by filtration [22-24]. The samples were filtered with Millipore Durapore ${ }^{\circledR}$ membranes with a nominal pore size of 0.45 and $0.2 \mu \mathrm{m}$ to eliminate large aggregates. 
The intensity autocorrelation function, $G_{2}(t)$, was measured at an angle of $15^{\circ}$. The autocorrelation function of the electric field $g_{1}(t)$ was determined from $G_{2}(t)$ using the Siegert relation,

$$
G_{2}(t)=A\left\{1+B g_{1}^{2}(t)\right\}
$$

where $B$ is an instrument parameter and $A$ is the uncorrelated scattering intensity. For monodispersed particles,

$$
\begin{gathered}
g_{1}(t)=\exp (-\Gamma t)=\exp \left(-D q^{2} t\right) \\
q=\left(4 \pi n / \lambda_{0}\right) \sin (\theta / 2)
\end{gathered}
$$

where $q$ is the magnitude of the scattering vector, $\Gamma$ is the average decay rate, $D$ is the translational diffusion coefficient, $\lambda_{0}$ is the wavelength of the incident light, $n$ is the refractive index of the solvent, and $\theta$ is the angle of observation. The distribution of molar masses of the BG macromolecules leads to exponential distributions. In these cases of superposition of exponentials functions, their distribution can be obtained by inverse Laplace transformation of $g_{1}(t)$ using the CONTIN program (swMATH, Berlin, Germany) [22-24].

The hydrodynamic radius $\mathrm{R}_{\mathrm{HDLS}}$ of the particles and macromolecules can be calculated from $D$ using the Stokes-Einstein equation [25]:

$$
R_{H D L S}=\frac{k_{B} T}{6 \pi D \eta}
$$

where $k_{B}$ is the Boltzmann constant, $T$ is the temperature $(\mathrm{K}), \eta$ is the viscosity solution (poise), and $D$ is the diffusion coefficient $\left(\mathrm{cm}^{2} \mathrm{~s}^{-1}\right)$.

The molecular weight is calculated using the following equation [25]:

$$
M_{D}=\left(\frac{D}{K_{D}}\right)^{-1 / a_{D}}
$$

where $K_{D}$ and $a_{D}$ are the constants of the solvent-polysaccharide system, with $K_{D}=0.0016157 \mathrm{~cm}^{2} / \mathrm{s}$ and $a_{D}=0.5413$.

\subsection{Intrinsic Viscosity Measurement}

Solutions were analyzed using an Ubbelohde 1B viscometer (IVA, Buenos Aires, Argentina). The temperature was controlled using a thermostatic bath (Haake 1C, Karlsruhe, Germany). The capillary viscometer was filled with an aliquot of each sample solution and the temperature was equilibrated for $20 \mathrm{~min}$. Flow times were taken as the average of four readings.

For a Newtonian fluid, viscosity ( $\eta$, poise) can be calculated based on Poiseuille's law (Matsuoka and Cowman [26]):

$$
\eta=A \rho t
$$

where $\rho$ is the density of the solution $\left(\mathrm{g} \mathrm{cm}^{-3}\right), A$ is the calibration constant $\left(\mathrm{cm}^{2} \mathrm{~s}^{-2}\right)$, and $t$ is the draining time or flow time of the solution (s). The Hagenbach-Couette method of time correction is used to correct errors in the viscosity measurements, with the $t_{H}$ calculated as $0.82 \mathrm{~s}$.

The $\eta_{r}$ (relative viscosity) is the ratio of the viscosity of the solution and the viscosity of the solvent:

$$
\eta=\frac{\rho t}{\rho_{0} t_{0}}
$$

where $\rho_{0}$ and $\mathrm{t}_{0}$ are the density and flow time of pure water, respectively.

The specific viscosity $\left(\eta_{s p}\right)$ is obtained from the relative viscosity: $\eta_{s p}=\eta_{r}-1$. 
The intrinsic viscosity, denoted by $[\eta]$, is defined as

$$
[\eta]=\lim _{c \rightarrow 0} \frac{\eta_{s p}}{c}=\lim _{c \rightarrow 0} \frac{1}{c} \ln \eta_{r}
$$

where $c$ is the biopolymer concentration $\left(\mathrm{g} \mathrm{cm}^{-3}\right)$. The plot of $\eta_{s p} / c$ versus $c$ or $1 / c \ln \eta_{r}$ versus $c$ often yields a straight line with the intercept being $[\eta]$.

The Huggins equation is

$$
\frac{\eta_{s p}}{c}=[\eta]+k_{H}[\eta]^{2} c
$$

where $k_{H}$ is the dimensionless Huggins constant (Sun, [27]). Some other equations used for determination of $[\eta]$ are:

$$
\begin{aligned}
\text { Kraemer } \frac{1}{c} \ln \eta_{r} & =[\eta]+k_{K}[\eta]^{2} c \\
\text { Schulz-Blaschke } \frac{\eta_{s p}}{c} & =[\eta]+k_{S-B}[\eta] \eta_{s p} \\
\text { Martin } \frac{\eta_{s p}}{c} & =[\eta] e^{k_{M} c[\eta]}
\end{aligned}
$$

The Mark-Houwink-Kuhn-Sakurada (MHKS) equation gives the relation between intrinsic viscosity and molecular weight:

$$
[\eta]=k M_{v}^{a}
$$

where $k$ and $a$ are both constants. The MHKS equation is applicable to many polymers and biopolymers, and it is extensively used for determining molecular weight. The constants $k$ and $a$ both vary depending on the polymer and solvent, as well as upon the temperature of the viscometric determination. The MHKS exponent is related to the three-dimensional conformation of a macromolecule in a given solvent. The values of $\boldsymbol{a}$ of 0.5 represent a sphere in an ideal solvent; $0.5-0.8$ a random coil in a good solvent; and 0.8-2 a rod-like conformation (Harding [28,29]; Masuelli [30]).

The corresponding value of "hydration" $(\delta)$ is defined by

$$
\delta=\left(v_{s p}-\bar{v}\right) \rho_{0}
$$

where $v_{s p}$ is the specific volume $\left(\mathrm{cm}^{3} \mathrm{~g}^{-1}\right)$ and is defined as

$$
v_{s p} \cong \frac{3 M v_{H}}{4 \pi}
$$

where $v_{\mathrm{H}}$ is hydrodynamic volume $\left(\mathrm{cm}^{3}\right)$ from measured $\mathrm{R}_{\mathrm{H}}$, and $M$ is the molecular weight (Da or $\mathrm{g} \mathrm{mol}^{-1}$ ) (Masuelli [31]). The magnitude of $\bar{v}$ can be determined by density measurements varying the biopolymer-water ratio as

$$
\bar{v}=\left(\frac{1-\frac{\partial \rho}{\partial \rho}}{\rho_{0}}\right)
$$

There are two molecular contributions to the intrinsic viscosity: one from the shape and the other from the size or volume, as summarized by the equation

$$
v_{a-b}=\frac{[\eta]}{v_{s p}}
$$

The viscosity increment $v_{a-b}$ is a universal shape function or Simha number, and it is related to the particle shape. For its experimental measurement, it requires the measurement of $v_{s p}, \bar{v}, \delta, \rho_{0}$ and [ $\left.\eta\right]$ (García de la Torre and Carrasco [32], Ortega and García de la Torre [33]). 


\section{Results and Discussion}

A three-dimensional representation of the schematic structure proposed by Cerezo et al. [6] is shown in Figure 1. The polysaccharide is mainly a polyxylose chain.

a

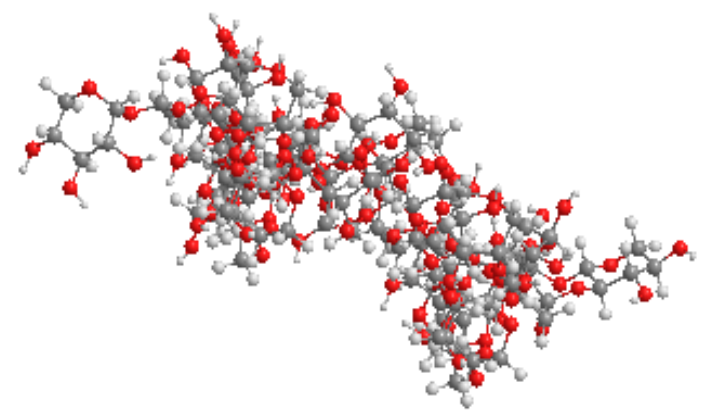

b

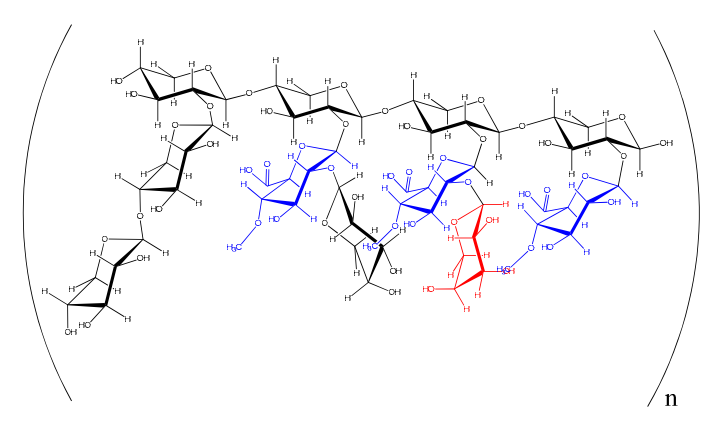

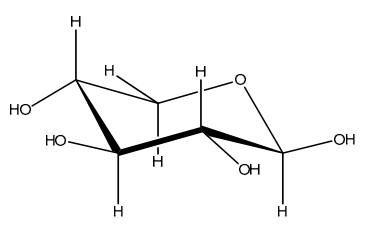

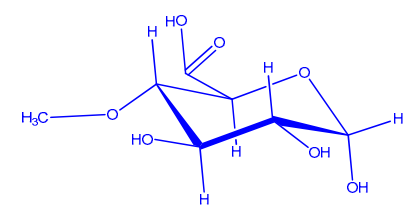

$\alpha-\mathrm{D}-$ Glucuronic Acid

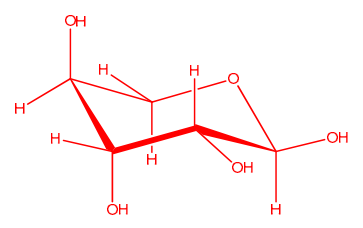

$\beta$-L-Arabinose

Figure 1. (a) Three-dimensional schematic representation of chemical structure of BG (chain portion: black = carbon; red = oxygen; gray = hydrogen); (b) two-dimensional structure.

The molecular weight of a biopolymer is very important, since it defines many of its physicochemical properties. Some examples of these properties include transitional temperatures in the different polymer phases, and mechanical properties such as strength, stiffness, toughness, viscoelasticity and electroviscosity.

\subsection{SEC Determination}

Retention times for $\mathrm{BG}$ as determined by SEC are $\mathrm{A}=7.31, \mathrm{~B}=9.45, \mathrm{C}=11.75$ and $\mathrm{D}=12.71 \mathrm{~min}$, with the contributions of each one being $90.14 \%, 0.04 \%, 0.18 \%$ and $9.64 \%$, respectively (Figure 2), and where $\mathrm{A}$ is the distribution of polysaccharide molecular weight produced by BG. The retention times of molecular weight distribution A vary from 6.75 to $8 \mathrm{~min}$, which translates to a molecular weight distribution of $1300-2550 \mathrm{~kg} \mathrm{~mol}^{-1}$. The retention time of arabic gum was 7.56 minutes with an $\mathrm{M}_{\mathrm{wv}}$ of $687 \mathrm{~kg} \mathrm{~mol}^{-1}$ by the viscometric method [34]. 


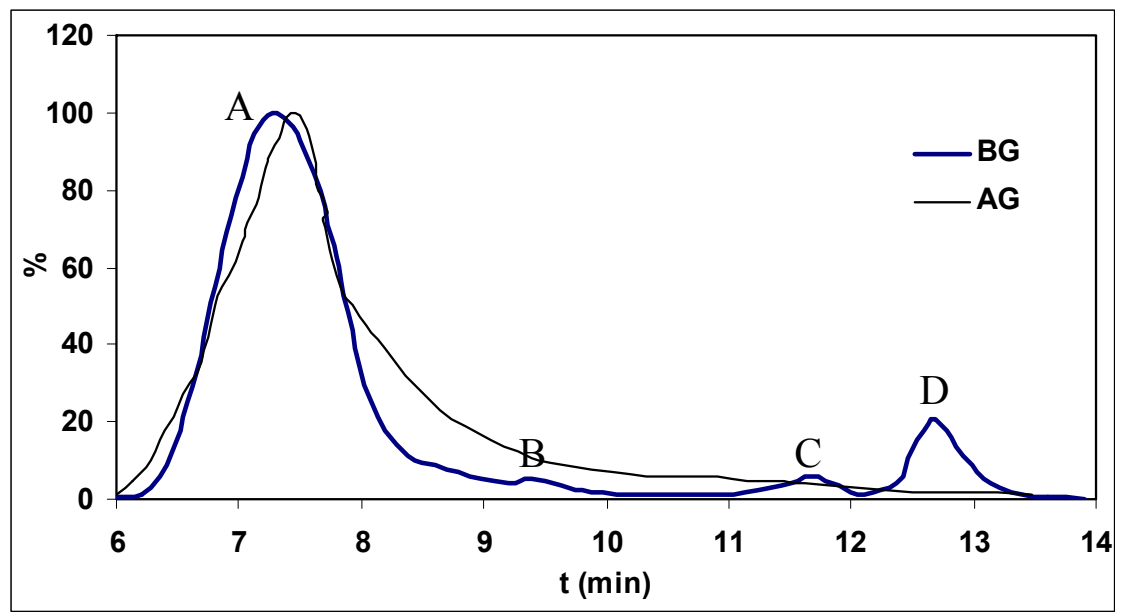

Figure 2. Chromatogram of BG and AG.

Variation in the hydrolysis caused displacement to higher retention times. The yields from purification of the polysaccharide, calculated from the areas under the curve, were $99.47 \%$ for BG 0.01 , $93.81 \%$ for BG $0.05,90.20 \%$ for BG 0.1 , and $16.08 \%$ for BG 0.5 .

Equation (18) shows a linear relationship between retention time $\left(t_{r}, \mathrm{~min}\right)$ and molecular weight of BG hydrolysates, with a standard deviation of 0.9949 :

$$
\ln M_{w}=-42.208 \ln t_{r}+98.822
$$

Figure 3 shows a shift to lower retention times as the hydrolysis becomes stronger. A remarkable rupture takes place in the higher-molecular-weight polysaccharide when hydrolysis is performed with a hydrochloric acid concentration of $0.5 \mathrm{M}$, and the molecular weight shifts to approximately to $700 \mathrm{~g} / \mathrm{mol}$.

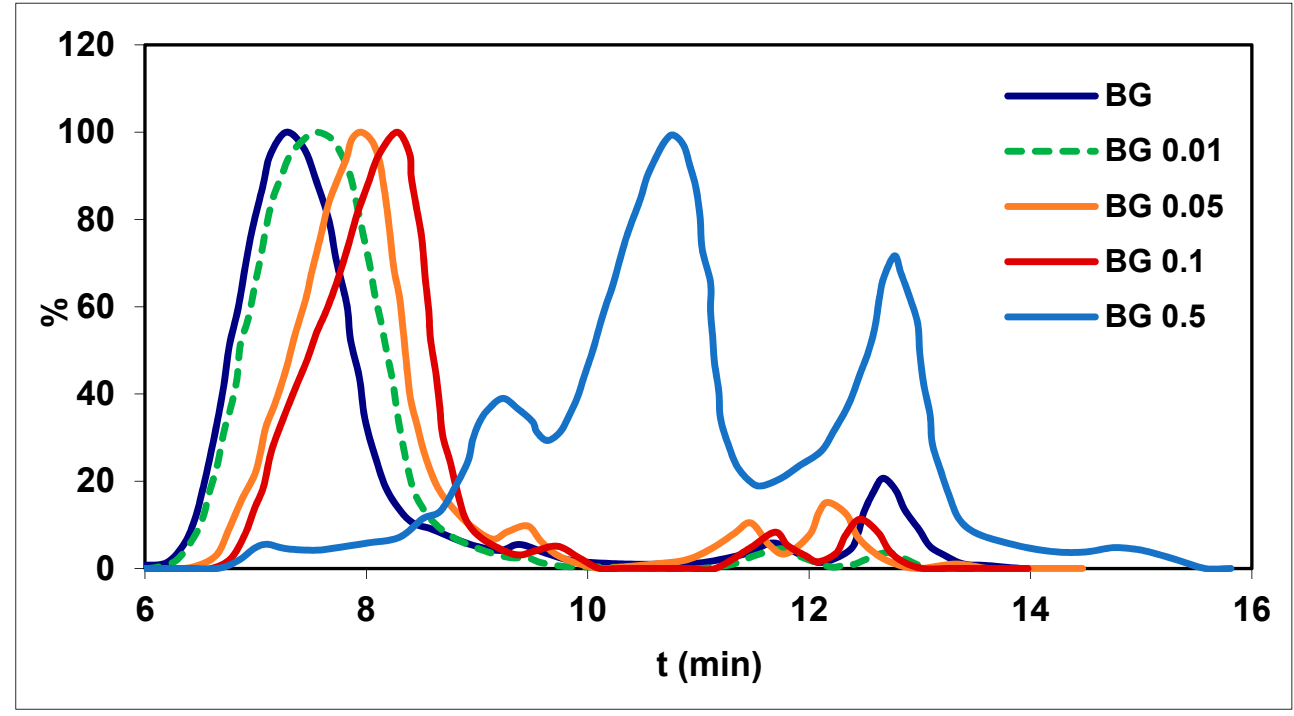

Figure 3. SEC chromatogram of BG hydrolysates.

\subsection{Intrinsic Viscosity and Density}

Intrinsic viscosity is a measurement of the hydrodynamic volume occupied by a macromolecule, which is closely related to the size and configuration of the macromolecular chain. Table 1 shows the flow times as a function of BG concentration, measured using a capillary viscometer. The densities and relative viscosities of the solutions are also reported. 
Table 1. Relative viscosity and density data as a function of BG concentration.

\begin{tabular}{cccc}
\hline$c\left(\mathrm{~g} \mathrm{~cm}^{-3}\right)$ & $\boldsymbol{t}(\mathrm{s})$ & $\rho\left(\mathrm{g} \mathrm{cm}^{-3}\right)$ & $\eta_{r}$ \\
\hline 0.0010 & 46.44 & 0.9988 & 1.052451 \\
0.0025 & 49.79 & 0.9992 & 1.128822 \\
0.0050 & 55.11 & 1.0002 & 1.250686 \\
0.0075 & 60.15 & 1.0011 & 1.366294 \\
0.0100 & 64.92 & 1.0020 & 1.475969 \\
\hline
\end{tabular}

Intrinsic viscosity was estimated through a plot of specific viscosity, or a related value, versus concentration, depending upon the method used (Equations (4)-(7)). The plot gives a straight line with the intercept being [ $\eta]$ (Morris et al. [35]).

Table 2 shows the intrinsic viscosity values obtained for BG solutions at $25^{\circ} \mathrm{C}$ through a variety of correlations. All of the intrinsic viscosity values calculated using the various methods were compared against the Huggins value (Equation (4)), normally used as a reference. It is noteworthy that all of the methods showed a low relative error (RE\%).

Table 2. Intrinsic viscosity obtained with different methods.

\begin{tabular}{ccccc}
\hline & Huggins & Kraemer & Schulz-Blaschke & Martin \\
\hline$[\eta]\left(\mathrm{cm}^{3} / \mathrm{g}\right)$ & 52.91 & 51.99 & 53.02 & 52.96 \\
$\mathrm{RE} \%$ & - & 1.7388 & 0.2079 & 0.0908 \\
\hline
\end{tabular}

The Huggins coefficient is a decreasing function of the viscosity radius expansion factor $\alpha \eta=[\eta] /[\eta]_{0}$, where $\left([\eta]_{0}\right)$ is the intrinsic viscosity for chains unperturbed by the excluded volume effect in the theta state, and ([ $\eta])$ for chains perturbed by this effect in good solvent systems. As the expansion factor for these systems is an increasing function of the molecular weight and the strength of the polymer-solvent interaction, the Huggins coefficient should be lower in good solvents and when molecular weight is high. In polyvinyl-alcohol solutions, the Huggins coefficient values obtained are attributed to the association of chains of the polymers through hydrogen bonds (Lawandowska et al. [36]). BG adopts a spherical conformation with very strong internal interactions due mainly to intramolecular hydrogen bonds. Interaction with the solvent takes place through polar groups accessible at the molecular surface, and is modified by salts and $\mathrm{pH}$. The highly polar characteristics in polysaccharides or polyelectrolytes generate atypical behavior in relation to water. The complexity of the inter- and intramolecular interactions presents in the BG-water system makes a simple interpretation for the values of hydrodynamic parameters rather impossible to elaborate. Although the results displayed of $k_{H}$ do not match this value, they are similar to many others reported in the literature, such as by Curvale et al. [37] for bovine serum albumin, and Chenlo et al. [38] for tragacanth, guar gum and methylcellulose.

The MHKS parameters obtained were $\boldsymbol{a}=0.4133$ and $k=0.1347 \mathrm{~cm}^{3} \mathrm{~g}^{-1}$; these values indicate that BG shows ideal behavior in water and that it takes spherical conformation. The $a$ value indicates that the biopolymer adopts a spherical conformation in aqueous solution. This is due to a highly branched structure or intramolecular interactions. The $k$ parameter depends predominantly on the geometry of the inter-residue linkages within the biopolymer chain. The polysaccharides, in which the bonds to and from each residue are directly opposite each other across the sugar ring, generally have highly expanded coil dimensions and high values for $\boldsymbol{k}$. Similar examples include guar gum, chitin and chitosan, pectin, cellulose and its derivatives, alginate, and locust bean gum (Lapasin and Pricl, [39]).

Anderson and Rahman [40] studied the intrinsic viscosity as a function of molecular weight for acacia gums and found the following MHKS parameters: $\boldsymbol{k}=0.013 \mathrm{~cm}^{3} \mathrm{~g}^{-1}$ and $\boldsymbol{a}=0.54$. These values were used by Idris et al. [41], and more recently by Al-Assaf et al. [42-44] and Savary et al. [45] for different acacia tree exudates. Sanchez et al. [46,47] reported $k=5.9 \times 10^{-4} \mathrm{~cm}^{3} \mathrm{~g}^{-1}$ and $\boldsymbol{a}=0.46$. 
These data demonstrate poorly differentiated behavior between arabic gum and brea gum, meaning that both gums are spherical in shape but differ little in their hydrodynamic properties.

The hydrodynamic values of $\bar{v}, R_{H}, v_{s p}, v_{a-b}, p$ and $\delta$ obtained for BG are shown in Table 3 .

Table 3. Hydrodynamics data of BG solutions $\left(\bar{v}, R_{H}, v_{s p}, v_{a-b}, p, \delta\right.$, and $\left.p\right)$.

\begin{tabular}{ccc}
\hline $\bar{v}\left(\mathrm{~cm}^{3} / \mathrm{g}\right)$ & $R_{H}(\mathrm{~nm})$ & $\delta(\mathrm{g} / \mathrm{g})$ \\
\hline 0.6424 & 32.49 & 20.5483 \\
\hline$v_{s p}\left(\mathrm{~cm}^{3} / \mathrm{g}\right)$ & $v_{a-b}$ & $p$ \\
\hline 21.1640 & 2.5031 & 1.0524 \\
\hline
\end{tabular}

The Simha and Perrin numbers confirm that this biopolymer has a spherical shape with $R_{H}=32.49 \mathrm{~nm}$. In turn, the values of $\delta$ support the idea that BG is a hyperbranched biopolymer (Morris et al. [35]). The hydrophilicity of this biopolymer is responsible for the large hydration value. The parameter commonly used to explain such unusual phenomena is the coefficient of expansion $\left(\alpha_{\eta}\right)$, which, in this case, presents a value of 1.0443. This confirms that the BG-water system is ideal, and that BG is presented as a nonextended macromolecule. These results also explain the findings of Bertuzzi et al. [4], since the BG presented low viscosity even at high concentrations of polysaccharide, due to its spherical and compact shape.

Table 4 shows that acid hydrolysis degrades this polysaccharide. The BG hydrolysates showed a decrease in the molecular weight of the polysaccharide (molecular weight determined by SEC), along with a consequent decrease in the intrinsic viscosity.

Table 4. Molecular weight determinates for intrinsic viscosity by BG hydrolysis.

\begin{tabular}{cccccc}
\hline BG Hydrolyzed & $\boldsymbol{t}_{\boldsymbol{s}}(\mathbf{s})$ & $\boldsymbol{\eta}_{\boldsymbol{r}}$ & $\eta_{\boldsymbol{s} \boldsymbol{p}}$ & {$[\boldsymbol{\eta}] \mathbf{( \mathbf { c m } ^ { 3 } / \mathbf { g } )}$} & $\boldsymbol{R}_{\boldsymbol{H}}(\mathbf{n m})$ \\
\hline BG 0.01 & 53.09 & 1.2416 & 0.24158 & 44.8958 & 25.12 \\
BG 0.05 & 45.79 & 1.0709 & 0.07086 & 13.8506 & 6.58 \\
BG 0.10 & 44.69 & 1.0451 & 0.04513 & 8.8948 & 4.00 \\
BG 0.50 & 42.96 & 1.0047 & 0.00467 & 1.9340 & 0.70 \\
\hline
\end{tabular}

The physicochemical parameter, theta temperature $(\theta)$, is related to a specific polymer/solvent system and is determined using a second virial coefficient (at a $\theta$ temperature, $A_{2}=0$ ) (Guner, [48]), phase separation/cloud point measurements, and the long-range interaction-temperature relationship (not measured in this work). These methods previously mentioned, in addition to the unperturbed dimensions, also allow determination of the long-range interaction parameter for viscometric-density studies. It is commonly known that the unperturbed dimension parameter depends only on the interactions between the polymer segments, and is completely independent of the molecular weight of the polymer, the temperature and the solvent (Guner \& Kibarer [49]). Theta temperature is determined by intrinsic viscosities at different temperatures using extrapolation methods.

The hydrodynamic radius of BG was found to decrease as the degree of hydrolysis increased, indicating a loss of chain stiffness or extension during hydrolysis. This finding is quite consistent with the noted changes in the exponent $\boldsymbol{a}$ value of the MHKS equation ( $\boldsymbol{a}$ value of 0.4133 ), leading to the conclusion that: 1) the chain stiffness, extension and steric hindrance of the backbone of the BG polysaccharide can be reduced due to the decrease in molecular weight with increasing degree of hydrolysis, and 2) BG is a hyperbranched macromolecule (with a certain polyelectrolyte characteristic).

Acid hydrolysis of BG causes the links in the chain of the polysaccharide to break down and a consequent decrease in molecular weight. The increase in acid concentration decreases the molecular weight substantially. This situation is explained since it has been used to obtain the molecular weight of BG and its hydrolysates, as well as to obtain the MHKS parameters through intrinsic viscosity measurements. 


\subsection{Dynamic Light Scattering Determination}

For over four decades, dynamic light scattering procedures have provided powerful tools for elucidating the size and conformation of macromolecular systems in solution. These procedures are particularly well suited for the analysis of relatively large, fairly monodisperse systems, and indeed we have extensively applied these techniques to systems of inorganic and organic nanoparticles, metal organic frameworks, polymers, proteins, polysaccharides, DNA, RNA, genes, prions, viruses and bacterial spores.

Figure 4 shows the size distribution of BG and its hydrolysates. $R_{\text {HDLS }}$ decreases with increasing hydrolysis degree, as this takes place using higher acid concentrations. An adequate response with $M_{D}$ was observed (see Table 5). When these data are compared with those obtained from the intrinsic viscosity measurements, it is observed that both present values with the same order.

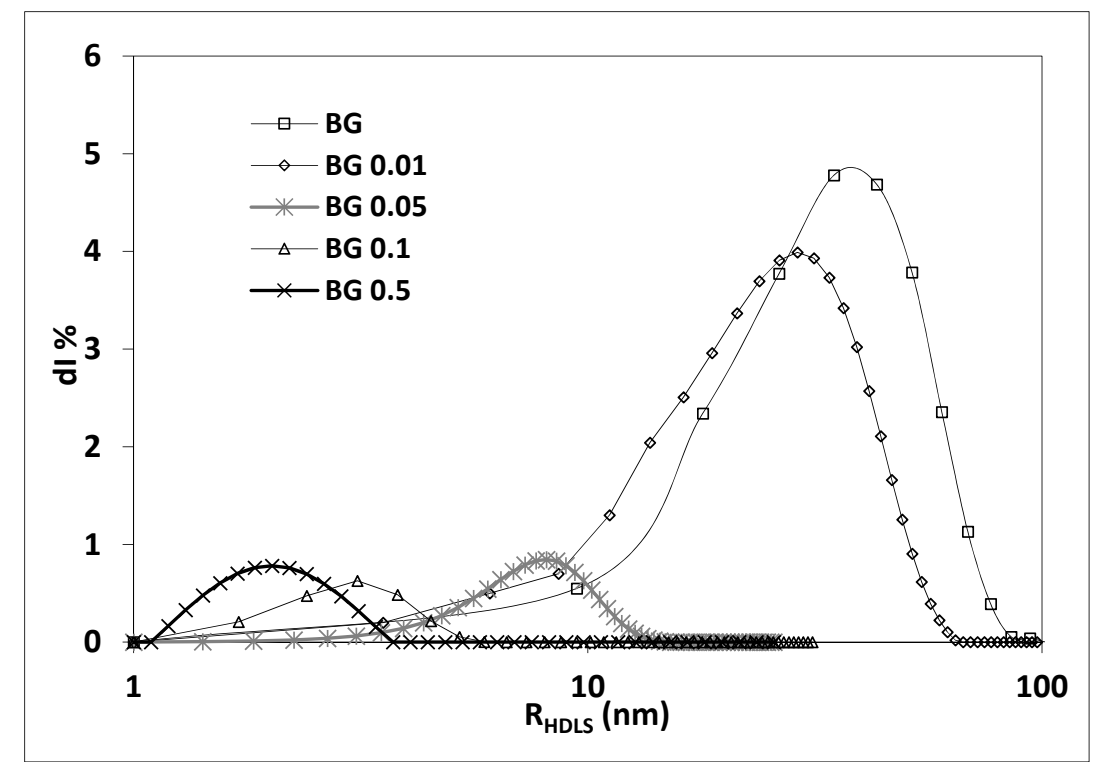

Figure 4. Size distribution of BG and its hydrolysates.

Table 5. $R_{H D L S(\max )}, R_{H D L S(m e a n)}$, and $M_{D}$ for BG and its hydrolysates.

\begin{tabular}{|c|c|c|c|c|c|}
\hline Sample & $R_{\text {HDLS(max) }}(\mathrm{nm})$ & $\mathbf{R}_{\text {HDLS(mean) }}(\mathrm{nm})$ & $M_{D}\left(\mathrm{~g} \mathrm{~mol}^{-1}\right)$ & $M_{w}\left(\mathrm{~g} \mathrm{~mol}^{-1}\right)$ & $M_{v}\left(\mathrm{~g} \mathrm{~mol}^{-1}\right)$ \\
\hline BG & 34.89 & 40.43 & $2,134,000$ & $2,320,000$ & $1,890,000$ \\
\hline BG 0.01 & 25.14 & 30.21 & $1,245,000$ & $1,249,000$ & $1,268,000$ \\
\hline BG 0.05 & 8.21 & 8.08 & 109,000 & 72,600 & 73,500 \\
\hline BG 0.10 & 3.11 & 3.16 & 19,200 & 25,500 & 26,000 \\
\hline BG 0.50 & 2.02 & 2.23 & 1000 & 700 & 622 \\
\hline
\end{tabular}

When Gaussian distributions are monodisperse, molecular weights of the biopolymer calculated are similar. For a monodisperse biopolymer, all molecular weight averages are the same and are equal to the unique molecular weight. Historically, this fact was not always recognized and thus it was sometimes difficult to reconcile conflicting experimental results, due to different concepts. When measuring the average molecular weight by intrinsic viscosity, the molecular weight is $M_{v}$ (and it is apparent); and when dynamic light scattering is used, the molecular weight is $\mathrm{M}_{\mathrm{DLS}}$. Until it was recognized that $\mathrm{M}_{\mathrm{V}} \neq \mathrm{M}_{\mathrm{DLS}}$, it was difficult to explain differing experimental results for the same biopolymer solution (Lee et al. [50]).

\section{Conclusions}

The Mark-Houwink-Kuhn-Sakurada parameters show that the BG polysaccharide acquires a spherical form in an ideal solvent such as water. The molecular weight calculated for BG was 
1,890,000 $\mathrm{g} \mathrm{mol}^{-1}$ by intrinsic viscosity, 2,320,000 $\mathrm{g} \mathrm{mol}^{-1}$ by SEC, and 2,134,000 $\mathrm{g} \mathrm{mol}^{-1}$ by DLS. The shape and size of the BG biopolymer are similar to arabic gum; although the $\mathrm{M}_{\mathrm{w}}$ of $A G$ is lower and the composition and hydrodynamic properties are slightly different. Acid hydrolysis experiments showed that the polysaccharide is easily degraded and its molecular weight decreases. Data of molecular weight values were used to obtain their hydrodynamic properties. The chain stiffness and steric hindrance of the backbone of the BG polysaccharide can be reduced with increasing degree of hydrolysis. BG is a hyperbranched and compact biopolymer. This knowledge justifies the rheological behavior of BG solutions and is important to define applications.

Author Contributions: Resources, M.A.B. and A.O.; Investigation, A.S.; Writing-Review \& Editing, M.A.M.

Acknowledgments: The authors thank the following institutions in Argentina: Universidad Nacional de San Luis, Universidad Nacional de Salta, Agencia Nacional de Promoción Científica y Tecnológica (ANPCyT-FONCyT), Laboratorio de Membranas y Biomateriales-Instituto de Física Aplicada-CONICET-UNSL, and Instituto de Investigaciones para la Industria Química-CONICET-UNSa.

Conflicts of Interest: The authors declare no conflict of interest.

\section{References}

1. Wareing, M.V. Exudates gums. In Thickening and Gelling Agents for Food; Imeson, A.P., Ed.; Springer Science \& Business Media: Hong Kong, China, 1999; pp. 86-118.

2. Yaseen, E.I.; Herald, T.J.; Aramouni, F.M.; Alavi, S. Rheological properties of selected gum solutions. Food Res. Int. 2005, 38, 111-119. [CrossRef]

3. Verbeken, D.; Dierckx, S.; Dewettinck, K. Exudate gums: Occurrence, production, and applications. Appl. Microbiol. Biotechnol. 2003, 63, 10-21. [CrossRef] [PubMed]

4. Bertuzzi, M.A.; Slavutsky, A.M.; Armada, M. Physicochemical characterisation of the hydrocolloid from Brea tree (Cercidium praecox). Int. J. Food Sci. Technol. 2012, 47, 776-782. [CrossRef]

5. von Müller, A.R.; López, C.B.; Eynard, A.R.; Guzmán, C.A. Subchronic toxicological evaluation of brea gum (Parkinsonia praecox) as a food additive in BALB/c mice. Drug Chem. Toxicol. 2009, 32, 307-311. [CrossRef]

6. Cerezo, A.S.; Stacey, M.; Webber, J.M. Some Structural Studies of Brea Gum (an Exudate from Cercidium Australe Johnst.). Carbohydr. Res. 1969, 9, 505-517. [CrossRef]

7. Ministerio de Agricultura, Ganadería y Pesca. Goma Brea: Un Producto con Potencial para el Desarrollo de la Economía Regional; Subsecretaría de Desarrollo de Economías Regionales, Universidad Nacional de Salta: Salta, Argentina, 2010.

8. De Pinto, G.; Rodriguez, O.; Martinez, M.; Rivas, C. Composition of cercidium praecox gum exudates. Biochem. Syst. Ecol. 1993, 21, 297-300. [CrossRef]

9. De Pinto, G.L.; Martínez, M.; Rivas, C. Chemical and spectroscopic studies of cercidium praecox gum exudate. Carbohydr. Res. 1994, 260, 17-25. [CrossRef]

10. Tischer, $\mathrm{C}$. The free reducing oligosaccharides of gum arabic: Aids for structural assignments in the polysaccharide. Carbohydr. Polym. 2002, 47, 151-158. [CrossRef]

11. Wang, Q.; Burchard, W.; Cui, S.W.; Huang, X.; Phillips, G.O. Solution properties of conventional gum arabic and a matured gum arabic (acacia (sen) super gum). Biomacromolecules 2008, 9, 1163-1169. [CrossRef] [PubMed]

12. Castel, V.; Zivanovic, S.; Jurat-Fuentes, J.L.; Santiago, L.G.; Rubiolo, A.C.; Carrara, C.R.; Harte, F.M. Chromatographic fractionation and molecular mass characterization ofcercidium praecox(brea) gum. J. Sci. Food Agric. 2016, 96, 4345-4350. [CrossRef] [PubMed]

13. Bertuzzi, M.A.; Slavutsky, A.M. Formulation and Characterization of Film Based on Gum Exudates from Brea Tree (Cercidium praecox). J. Food Sci. Eng. 2013, 3, 113-122.

14. Slavutsky, A.M.; Bertuzzi, M.A.; Armada, M.; García, M.G.; Ochoa, N.A. Preparation and characterization of montmorillonite/brea gum nanocomposites films. Food Hydrocolloids 2014, 35, 270-278. [CrossRef]

15. Slavutsky, A.M.; Bertuzzi, M.A. Thermodynamic study of water sorption and water barrier properties of nanocomposite films based on brea gum. Appl. Clay Sci. 2015, 108, 144-148. [CrossRef]

16. Spotti, M.L.; Cecchini, J.P.; Spotti, M.J.; Carrara, C.R. Brea gum (from cercidium praecox) as a structural support for emulsion-based edible films. LWT-Food Sci. Technol. 2016, 68, 127-134. [CrossRef] 
17. Mellinas, C.; Valdés, A.; Ramos, M.; Burgos, N.; del Carmen Garrigós, M.; Jiménez, A. Active edible films: Current state and future trends. J. Appl. Polym. Sci. 2016, 133. [CrossRef]

18. López, E.P.; Jiménez, P.L. Effect of different proportions of brea gum in the functional characteristics of wheat flour starch: Impact on the physical quality of bread. Food Sci. Technol. (Campinas) 2016, 36, 83-89. [CrossRef]

19. Castel, V.; Rubiolo, A.C.; Carrara, C.R. Droplet size distribution, rheological behavior and stability of corn oil emulsions stabilized by a novel hydrocolloid (brea gum) compared with gum arabic. Food Hydrocolloids 2017, 63, 170-177. [CrossRef]

20. López, E.P.; Goldner, M.C. Influence of storage time for the acceptability of bread formulated with lupine protein isolate and added brea gum. LWT-Food Sci. Technol. 2015, 64, 1171-1178. [CrossRef]

21. López, E.P.; Pérez, G.T.; Jiménez de Erramouspe, P.L.; Cuevas, C.M. Effect of Brea Gum on the characteristics of wheat bread at different storage times. Food Sci. Technol. (Campinas) 2013, 33, 745-752. [CrossRef]

22. Heineck, M.E.; Cardoso, M.B.; Giacomelli, F.C.; da Silveira, N.P. Evidences of amylose coil-to-helix transition in stored dilute solutions. Polymer 2008, 49, 4386-4392. [CrossRef]

23. Rojas, R.; Giacomelli, C.E. Effect of structure and bonding on the interfacial properties and the reactivity of layered double hydroxides and zn hydroxide salts. Colloids Surf. A: Physicochem. Eng. Asp. 2013, 419, 166-173. [CrossRef]

24. dos Santos, M.C.; Kroetz, T.; Dora, C.L.; Giacomelli, F.C.; Frizon, T.E.A.; Pich, C.T.; da Silva Pinto, L.; Soares, A.S.; Rodembusch, F.S.; Lima, V.R.; et al. Elucidating Bauhinia variegata lectin/phosphatidylcholine interactions in lectin-containing liposomes. J. colloid Interface Sci. 2018, 519, 232-241. [CrossRef]

25. Masuelli, M.A. Hydrodynamic Parameters of Strelitzia Gum. Colloids Interfaces 2018, 2, 45. [CrossRef]

26. Matsuoka, S.; Cowman, M.K. Equation of state for polymer solution. Polymer 2002, 43, 3447-3453. [CrossRef]

27. Sun, S.F. Physical Chemistry of Macromolecules: Basic Principles and Issues, 2nd ed.; Wiley: Hoboken, NJ, USA, 2004; pp. 165-184.

28. Masuelli, M.A. Viscometric study of pectin. Effect of temperature on the hydrodynamic properties. Int. J. Biological Macromol. 2011, 48, 286-291. [CrossRef] [PubMed]

29. Harding, S.E.; Varum, K.; Stoke, B.; Smidsrod, O. Molecular weight determination of polysaccharides. Adv. Carbohydr. Anal. 1991, 1, 63-144.

30. Harding, S.E. The Viscosity Intrinsic of Biological Macromolecules. Progress in Measurement, Interpretation and Application to Structure in Dilute Solution. Progr. Biophys. Mol. Biol. 1997, 68, 207-262. [CrossRef]

31. Masuelli, M.A. Study of Bovine Serum Albumin Solubility in Aqueous Solutions by Intrinsic Viscosity Measurements. Adv. Phys. Chem. 2013, 2013. [CrossRef]

32. Garcia de la Torre, J.; Carrasco, B. Universal size-independent quantities for the conformational characterization of rigid and flexible macromolecules. Progr. Colloid Polym. Sci. 1999, 113, 81-86.

33. Ortega, A.; García de la Torre, J. Equivalent radii and ratios of radii from solution properties as indicators of macromolecular conformation, shape, and flexibility. Biomacromolecules 2007, 8, 2464-2475. [CrossRef] [PubMed]

34. Masuelli, M.A. Hydrodynamic Properties of Whole Arabic Gum. Am. J. Food Sci. Technol. 2013, 1, 60-66.

35. Morris, G.A.; Patel, T.R.; Picout, D.R.; Ross-Murphy, S.B.; Ortega, A.; Garcia de la Torre, J.; Harding, S.E. Global hydrodynamic analysis of the molecular flexibility of galactomannans. Carbohydr. Polym. 2008, 72, 356-360. [CrossRef]

36. Lewandowska, K.; Staszewska, D.U.; Bohdanecký, M. The huggins viscosity coefficient of aqueous solution of poly(vinyl alcohol). Eur. Polym. J. 2001, 37, 25-32. [CrossRef]

37. Curvale, R.; Masuelli, M.; Padilla, A.P. Intrinsic viscosity of bovine serum albumin conformers. Int. J. Biological Macromol. 2008, 42, 133-137. [CrossRef] [PubMed]

38. Chenlo, F.; Moreira, R.; Pereira, G.; Silva, C. Rheological modelling of binary and ternary systems of tragacanth, guar gum and methylcellulose in dilute range of concentration at different temperatures. LWT-Food Sci. Technol. 2009, 42, 519-524. [CrossRef]

39. Lapasin, R.; Pricl, S. Rheology of polysaccharide systems. In Rheology of Industrial Polysaccharides: Theory and Applications; Glasgow: Blackie, UK, 1995; pp. 250-494.

40. Anderson, D.M.W.; Rahman, S. Studies on uronic acid materials: Part XX. The viscosity-molecular weight relationship for acacia gums. Carbohydr. Res. 1967, 4, 298-304. [CrossRef] 
41. Idris, O.H.M.; Williams, P.A.; Phillips, G.O. Characterisation of gum from acacia senegal trees of different age and location using multidetection gel permeation chromatography. Food Hydrocolloids 1998, 12, 379-388. [CrossRef]

42. Assaf, S.; Phillips, G.; Williams, P. Studies on acacia exudate gums. Part I: The molecular weight of gum exudate. Food Hydrocolloids 2005, 19, 647-660. [CrossRef]

43. Al-Assaf, S.; Phillips, G.O.; Williams, P.A. Studies on acacia exudate gums: Part ii. Molecular weight comparison of the Vulgares and Gummiferae series of Acacia gums. Food Hydrocolloids 2005, 19, 661-667. [CrossRef]

44. Al-Assaf, S.; Hassan, E.A.; Phillips, G.O.; Williams, P.A. Studies on Acacia gums: Part III molecular weight characteristics of Acacia seyal var. seyal and Acacia seyal var fistula. Food Hydrocolloids 2005, 19, 669-677.

45. Savary, G.; Hucher, N.; Bernadi, E.; Grisel, M.; Malhiac, C. Relationship between the emulsifying properties of acacia gums and the retention and diffusion of aroma compounds. Food Hydrocolloids 2010, 24, 178-183. [CrossRef]

46. Sanchez, C.; Renard, D.; Robert, P.; Schmitt, C.; Lefebvre, J. Structure and rheological properties of acacia gum dispersions. Food Hydrocolloids 2002, 16, 257-267. [CrossRef]

47. Sanchez, C.; Schmitt, C.; Kolodziejczyk, E.; Lapp, A.; Gaillard, C.; Renard, D. The acacia gum arabinogalactan fraction is a thin oblate ellipsoid: A new model based on small-angle neutron scattering and ab initio calculation. Biophys. J. 2008, 94, 629-639. [CrossRef] [PubMed]

48. Guner, A. Unperturbed dimensions and theta temperature of dextran in aqueous solutions. J. Appl. Polym. Sci. 1999, 72, 871-876. [CrossRef]

49. Güner, A.; Kibarer, G. The important role of thermodynamic interaction parameter in the determination of theta temperature, dextran/water system. Eur. Polym. J. 2001, 37, 619-622. [CrossRef]

50. Lee, K.Y.; Bouhadir, K.H.; Mooney, D.J. Evaluation of chain stiffness of partially oxidized polyguluronate. Biomacromolecules 2002, 3, 1129-1134. [CrossRef] [PubMed]

(C) 2018 by the authors. Licensee MDPI, Basel, Switzerland. This article is an open access article distributed under the terms and conditions of the Creative Commons Attribution (CC BY) license (http:/ / creativecommons.org/licenses/by/4.0/). 